\title{
Nitric Oxide Signaling Contributes to Late-Phase LTP and CREB Phosphorylation in the Hippocampus
}

\author{
Yun-Fei Lu, ${ }^{1}$ Eric R. Kandel, ${ }^{1,2,3}$ and Robert D. Hawkins ${ }^{1,2}$ \\ ${ }^{1}$ Center for Neurobiology and Behavior, College of Physicians and Surgeons, Columbia University, ${ }^{2}$ New York State \\ Psychiatric Institute, and ${ }^{3}$ Howard Hughes Medical Institute, New York, New York 10032
}

Long-term potentiation (LTP) in the hippocampus has an early phase (E-LTP) that can be induced by one- or two-train tetanization, lasts $\sim 1 \mathrm{hr}$, and is cAMP-dependent protein kinase (PKA) and protein synthesis independent and a late phase (L-LTP) that can be induced by three- or four-train tetanization, lasts $>3 \mathrm{hr}$, and is reduced by inhibitors of PKA and of protein or RNA synthesis. Nitric oxide (NO) is thought to be involved in E-LTP, but until now there has been no information about the role of the NO-signaling pathway in L-LTP. We examined this question at the Schaffer collateral-CA1 synapses in slices of mouse hippocampus. An inhibitor of NO synthase blocked L-LTP induced by three-train tetanization and reduced L-LTP induced by four-train tetanization, whereas an inhibitor of PKA was more effective in blocking four-train L-LTP than three-train L-LTP. Three-train L-LTP was also blocked by inhibitors of guanylyl cyclase or cGMP-dependent protein kinase (PKG). Conversely, either NO or cGMP analogs paired with one-train tetanization produced late-phase potentiation, and the cGMPinduced potentiation was blocked by inhibitors of protein or RNA synthesis and an inhibitor of PKG, but not by an inhibitor of PKA. To test a possible downstream target of PKG, we examined changes in phospho-CRE-binding protein (phosphoCREB) immunofluorescence in the CA1 cell body area and obtained results similar to those of the electrophysiology experiments. These results suggest that NO contributes to L-LTP by stimulating guanylyl cyclase and cGMP-dependent protein kinase, which acts in parallel with PKA to increase phosphorylation of the transcription factor CREB.

Key words: nitric oxide; guanylyl cyclase; cGMP-dependent protein kinase; long-term potentiation; CREB; hippocampus
Long-term potentiation (LTP) is a long-lasting form of synaptic plasticity that is thought to contribute to some types of learning and memory (for review, see Bliss and Collingridge, 1993; Hawkins et al., 1993). Like memory (Davis and Squire, 1984; Kandel, 1989), LTP has been found to exhibit an early phase that is independent of protein and RNA synthesis and a late phase that is reduced by inhibitors of those processes (Frey et al., 1988; Huang and Kandel, 1994; Nguyen et al., 1994; Huang et al., 1996; Nguyen and Kandel, 1997). Early-phase LTP (E-LTP) can be induced by brief tetanization, such as one train of $100 \mathrm{~Hz}$ stimulation for $1 \mathrm{sec}$, and lasts $\sim 1 \mathrm{hr}$. By contrast, late-phase LTP (L-LTP) is usually induced by three or four trains of tetanization with 5-10 min between trains and lasts >3 hr (Frey et al., 1993; Huang and Kandel, 1994; Huang et al., 1996). Early- and latephase LTP also involve different signaling pathways. For example, in the CA1 region of the hippocampus, L-LTP is reduced by inhibitors or genetic disruption of cAMP-dependent protein kinase (PKA), whereas E-LTP is usually not PKA dependent (Frey et al., 1993; Huang and Kandel, 1994; Huang et al., 1996; Abel et al., 1997; Nguyen and Kandel, 1997; Winder et al., 1998).

Nitric oxide (NO) is a diff usible molecule that can act as a novel type of intercellular messenger in the brain (Bredt and Snyder,

Received May 14, 1999; revised Sept. 10, 1999; accepted Sept. 15, 1999.

This research was supported by the National Institute of Mental Health Grant MH50733 and by a grant from the Howard Hughes Medical Institute. We thank K. Martin and L. Zablow for advice and assistance with the immunocytochemistry, K. Martin, S. Patterson, and D. Winder for their comments, and M. Pellan and H. Ayers for typing this manuscript.

Correspondence should be addressed to Dr. Robert D. Hawkins, Center for Neurobiology and Behavior, Columbia University, College of Physicians and Surgeons, 722 West 168th Street, New York, NY 10032. E-mail: rhawkins@pi.cpmc.columbia.edu.

Copyright $\odot 1999$ Society for Neuroscience $\quad 0270-6474 / 99 / 1910250-12 \$ 05.00 / 0$
1992) and may act as a retrograde messenger during the induction of LTP (for review, see Hawkins et al., 1998). A number of studies have shown that inhibitors of NO synthase (NOS), the enzyme for NO production, can prevent the induction of LTP under some experimental conditions. Knock-out of both the neuronal and endothelial isoforms of NOS (Son et al., 1996) or adenovirusmediated inhibition of the endothelial isoform (Kantor et al., 1996) can also block LTP. Conversely, exogenous NO can produce activity-dependent long-lasting potentiation either in hippocampal slices (Bohme et al., 1991; Zhuo et al., 1993; Malen and Chapman, 1997) or in the presynaptic neuron in dissociated cultures of hippocampal neurons (Arancio et al., 1996). However, all of these studies about the role of NO in LTP have focused on LTP lasting for $\sim 1 \mathrm{hr}$ (i.e., E-LTP). Behavioral studies have shown that NO is involved in learning several types of tasks, some of which are remembered for days (for review, see Hawkins, 1996), raising the question of whether NO signaling might also be involved in L-LTP. In the present study, we examined this question at the synapses from Schaffer collateral fibers onto CA1 pyramidal cells in slices of mouse hippocampus. Our results indicate that NO is involved in three-train L-LTP and to a lesser extent in four-train L-LTP and suggest that it contributes to L-LTP via the activation of guanylyl cyclase, cGMP-dependent protein kinase, and CRE-binding protein (CREB) phosphorylation. These results have revealed a new signaling pathway in the induction of L-LTP that appears to be parallel and complementary to the PKA-signaling pathway.

\section{MATERIALS AND METHODS}

Male C57BL6 mice aged 6-9 weeks were housed and killed in accordance with the guidelines of the Health Sciences Division of Columbia University. The brain was quickly removed and immersed in ice-cold 
artificial CSF (ACSF) bubbled with a gas mixture of $95 \% \mathrm{O}_{2}$ and $5 \%$ $\mathrm{CO}_{2}$, the hippocampus was dissected, and $400 \mu \mathrm{m}$ transverse slices were prepared. The slices were incubated in an interface recording chamber maintained at $28.5 \pm 0.5^{\circ} \mathrm{C}$ for at least $1.5 \mathrm{hr}$ before recording and were constantly subfused with gas-saturated ACSF at $1-1.5 \mathrm{ml} / \mathrm{min}$. The composition of the ACSF was as follows: $\mathrm{NaCl}, 124 \mathrm{~mm}$; KCl, $4.4 \mathrm{mM}$; $\mathrm{CaCl}_{2}, 2.5 \mathrm{~mm} ; \mathrm{MgSO}_{4}, 1.3 \mathrm{~mm} ; \mathrm{NaH}_{2} \mathrm{PO}_{4}, 1 \mathrm{~mm} ; \mathrm{NaHCO}_{3}, 26 \mathrm{~mm}$; and glucose, $10 \mathrm{~mm}$.

Electrophysiological experiments. To record the field EPSP, a glass micropipette filled with ACSF (1-5 M $\Omega$ resistance) was placed in the stratum radiatum of the CA1 region, and a bipolar tungsten-stimulating electrode was placed along the Schaffer collateral fibers. In two-pathway experiments, two stimulating electrodes were placed on opposite sides of the recording electrode, and stimulation from the two electrodes was delivered alternately. The intensity of the stimulation was adjusted to produce an EPSP with a slope that was $\sim 35 \%$ of maximum. The test stimulation was delivered once per minute $(0.017 \mathrm{~Hz})$. For inducing LTP, either single or multiple trains of stimulation at $100 \mathrm{~Hz}$ for $1 \mathrm{sec}$ were delivered at the same intensity as the test stimulation. In the experiments using picrotoxin, the $\mathrm{CA} 3$ region was surgically removed from the slice, and the ACSF was adjusted by increasing both $\mathrm{CaCl}_{2}$ and $\mathrm{MgSO}_{4}$ to 4 $\mathrm{mM}$ to reduce seizure activity.

NO solution was prepared as described previously (Zhuo et al., 1993). Briefly, NO gas was bubbled to saturation in helium-saturated distilled water and then diluted to $0.1-1.0 \mu \mathrm{M}$ in ACSF containing $30 \mathrm{units} / \mathrm{ml}$ superoxide dismutase. The NO solution was prepared immediately before use and injected directly into the recording chamber.

The following drugs were used: 8-bromo-cGMP (8-Br-cGMP), 8-(4chlorophenylthio)-cGMP (8-pCPT-cGMP), $\beta$-phenyl-1, $N^{2}$-etheno-8bromo-guanosine $3^{\prime}, 5^{\prime}$-cyclic monophosphothioate (Rp-8-Br-PETcGMPS), and Sp-adenosine 3',5'-cyclic monophosphothioate (SpcAMPS) from Biolog Life; KT5823 and KT5720 from Calbiochem (La Jolla, CA); anisomycin, actinomycin $\mathrm{D}, \mathrm{N}^{\omega}$-nitro-L-arginine, and picrotoxin from Sigma (St. Louis, MO); $1 H$-[1,2,4]oxadiazolo[4,3$\alpha$ ]quinoxalin-1-one (ODQ) from Alexis; and U0126 from Research Biochemicals (Natick, MA). The drugs were prepared as stock solutions and diluted in ACSF immediately before application. Rp-8-Br-PET-cGMPS, Sp-cAMPS, KT5823, KT5720, ODQ, and U0126 were prepared in DMSO, and actinomycin D was prepared in ethanol. The final concentration of the DMSO or ethanol was $0.1 \%$.

Data are shown as mean $( \pm$ SEM $)$ percent of the baseline EPSP slope. Data were analyzed using either $t$ tests to compare two conditions or ANOVA followed by planned comparisons of multiple conditions, and $p<0.05$ was considered significant.

Immunocytochemical experiments. Hippocampal slices were prepared and treated with tetanic stimulation and/or drugs exactly as described in the electrophysiological experiments. Either 1 or $60 \mathrm{~min}$ after the treatment, the slices were rapidly immersed in ice-cold $4 \%$ paraformaldehyde in PBS, $\mathrm{pH} 7.4$, and fixed for $60 \mathrm{~min}$. The slices were then washed three times in PBS, permeabilized in $0.3 \%$ Triton X-100 in PBS for $60 \mathrm{~min}$ at room temperature, and then washed three times in PBS again. The free aldehydes were quenched in $50 \mathrm{~mm}$ ammonium chloride in PBS for 20 min. Nonspecific antibody binding was blocked by incubation in $10 \%$ goat serum in PBS for $60 \mathrm{~min}$ at room temperature. The slices were then incubated with primary antibody, rabbit polyclonal anti-phospho-CREB (Upstate Biotechnology, Lake Placid, NY), diluted 1:100 in 10\% goat serum in PBS at $4^{\circ} \mathrm{C}$ for $36 \mathrm{hr}$. This antibody is thought to be relatively selective for phospho-CREB, although it may have some cross-reactivity with the related molecules CRE modulator (CREM) and activating transcription factor 1 (ATF-1) (Ginty et al., 1993). The slices were then washed six times in PBS, for $2 \mathrm{hr}$ each time. The slices were incubated in goat anti-rabbit antibody conjugated with indocarbocyanine (Jackson ImmunoResearch, West Grove, PA) diluted 1:100 in 10\% goat serum overnight at $4^{\circ} \mathrm{C}$. They were then washed again in PBS six times, for $2 \mathrm{hr}$ each time.

The slices were viewed using a Bio-Rad (Hercules, CA) MRC1000 laser confocal-scanning system coupled to a Zeiss Axiovert 100 inverted microscope. Images were taken using a $5 \times, 0.25$ numerical aperture (NA) or a $40 \times, 0.75$ NA water immersion objective. Kalman averages of five scans were collected for each image. The mean pixel intensity in the CA1 cell body area and in an apical dendritic area of CA3 that was relatively free of cell bodies was determined using Bio-Rad Comos software. The ratio of intensities in the two areas was determined in each slice to normalize for differences in background fluorescence. These values were in turn normalized to the values obtained from untreated control slices from the same animal. All data are presented as mean $( \pm$ SEM) percent of control. The experimental data were analyzed by a two-way ANOVA (treatment and time) followed by planned comparisons of individual conditions. The specificity of the immunofluorescence was confirmed by omitting the primary antibody, which resulted in a significant reduction in fluorescence intensity.

\section{RESULTS \\ NO signaling is involved in L-LTP}

Previous studies have shown that four trains of tetanic stimulation can induce long-lasting LTP (L-LTP) that is dependent on PKA in the CA1 region of mouse hippocampus (Abel et al., 1997; Winder et al., 1998). We first replicated those studies and found that four trains of $100 \mathrm{~Hz} / 1 \mathrm{sec}$ stimulation induced stable longlasting LTP (the EPSP slope was $227 \pm 17 \%$ of baseline $3 \mathrm{hr}$ after the end of tetanization; $n=5$; Fig. $1 A$ ) that was almost completely blocked by KT5720 $(1 \mu \mathrm{M})$, an inhibitor of PKA [117 \pm $7 \%$ at $3 \mathrm{hr} ; n=6 ; F_{(1,28)}=30.89 ; p<0.01$ compared with normal saline; Fig. $1 B$ ]. In agreement with previous studies, KT5720 also reduced an intermediate phase of LTP that is expressed within the first hour after multiple-train tetanization and is mechanistically distinct from both E-LTP and L-LTP (Blitzer et al., 1995, 1998; Winder et al., 1998). We then tested the effect of $\mathrm{N}^{\omega}$-nitroL-arginine (NO-Arg), an inhibitor of nitric oxide synthase. NOArg $(100 \mu \mathrm{M})$ applied at least $60 \mathrm{~min}$ before tetanic stimulation and throughout the experiment reduced L-LTP by four-train tetanization but did not completely block it $(147 \pm 10 \%$ at $3 \mathrm{hr}$; $n=6$; Fig. $1 A$ ). These results are consistent with those of Zhuo et al. (1998), who found that although NO-Arg completely blocked E-LTP by one-train tetanization and significantly reduced E-LTP by two-train tetanization, it only partially reduced LTP 60 min after four-train tetanization.

We next tested whether PKA and the NO-signaling pathway might contribute differently to L-LTP induced with a weaker stimulation protocol. Three trains of $100 \mathrm{~Hz} / 1 \mathrm{sec}$ stimulation with 5 min between trains induced stable L-LTP that was slightly smaller than four-train L-LTP $(193 \pm 21 \%$ at $3 \mathrm{hr} ; n=6$; Fig. $1 C)$ KT5720 reduced this L-LTP but did not completely block it $(138 \pm 17 \% ; n=5$; Fig. $1 D)$, suggesting that three-train L-LTP has a PKA-independent component. By contrast, NO-Arg almost completely blocked three-train L-LTP $[116 \pm 6 \%$ at $3 \mathrm{hr} ; n=6$; $F_{(1,28)}=16.28 ; p<0.01$ compared with normal saline; Fig. $\left.1 C\right]$. The results with KT5720 and NO-Arg with three-train tetanization were the reverse of those with four-train tetanization, as indicated by a significant drug $\times$ train number interaction in a two-way ANOVA $\left[F_{(1,19)}=6.67 ; p<0.05\right]$. These results suggest that NO signaling and PKA contribute preferentially to somewhat different components of L-LTP, with NO contributing importantly to three-train L-LTP and to a lesser extent to four-train L-LTP.

Previous studies have shown that NO paired with a weak tetanus $(50 \mathrm{~Hz} / 0.5 \mathrm{sec})$ induced LTP that lasted for at least 60 min (Zhuo et al., 1993). To test whether NO also contributes to the induction of L-LTP, we used a modified protocol in which we paired NO with a single $100 \mathrm{~Hz} / 1 \mathrm{sec}$ train of stimulation. Stimulation alone $(100 \mathrm{~Hz} / 1 \mathrm{sec})$ produced early-phase LTP $(130 \pm 14 \%$ at $60 \mathrm{~min} ; n=5)$ but not L-LTP $(114 \pm 9 \%$ at $3 \mathrm{hr})$. However, when NO was paired with one-train tetanization, stable late-phase potentiation was obtained $[163 \pm 15 \%$ at $3 \mathrm{hr} ; n=4$; $t(3)=4.20 ; p<0.05 ; t(7)=3.21 ; p<0.05$ compared with one-train alone; Fig. $2 A]$. These results, together with the inhibitory effect of NO-Arg on L-LTP induced by multiple-train tet- 
A

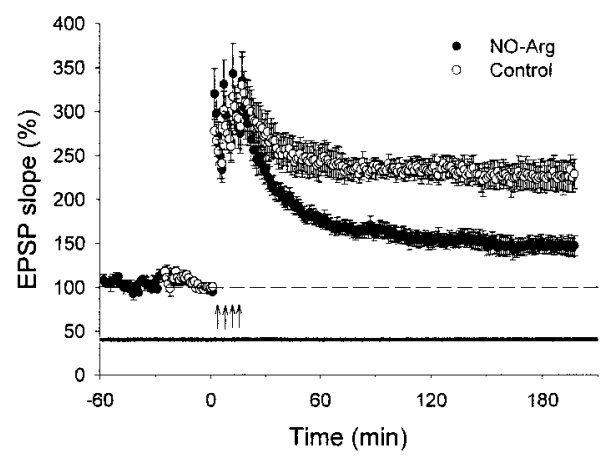

Figure 1. Inhibitors of NOS or PKA preferentially reduce L-LTP induced by different stimulation protocols. $A$, L-LTP induced by four trains of 100 $\mathrm{Hz} / 1 \mathrm{sec}$ tetanization (arrows) was reduced but not completely blocked by the NO synthase inhibitor NO-Arg (100 $\mu \mathrm{M}) . B$, Four-train L-LTP was blocked by the PKA inhibitor KT5720 $(1 \mu \mathrm{M})$. $C$, Three trains of $100 \mathrm{~Hz} / 1 \mathrm{sec}$ tetanization with 5 min between trains induced stable L-LTP that was blocked by NOArg. NO-Arg was applied at least $1 \mathrm{hr}$ before the tetanic stimulation and throughout the experiment. Insets, Representative field EPSPs before and $3 \mathrm{hr}$ after tetanic stimulation are shown. Calibration: $5 \mathrm{msec}, 1 \mathrm{mV}$. $D$, Three-train L-LTP was reduced but not completely blocked by KT5720.
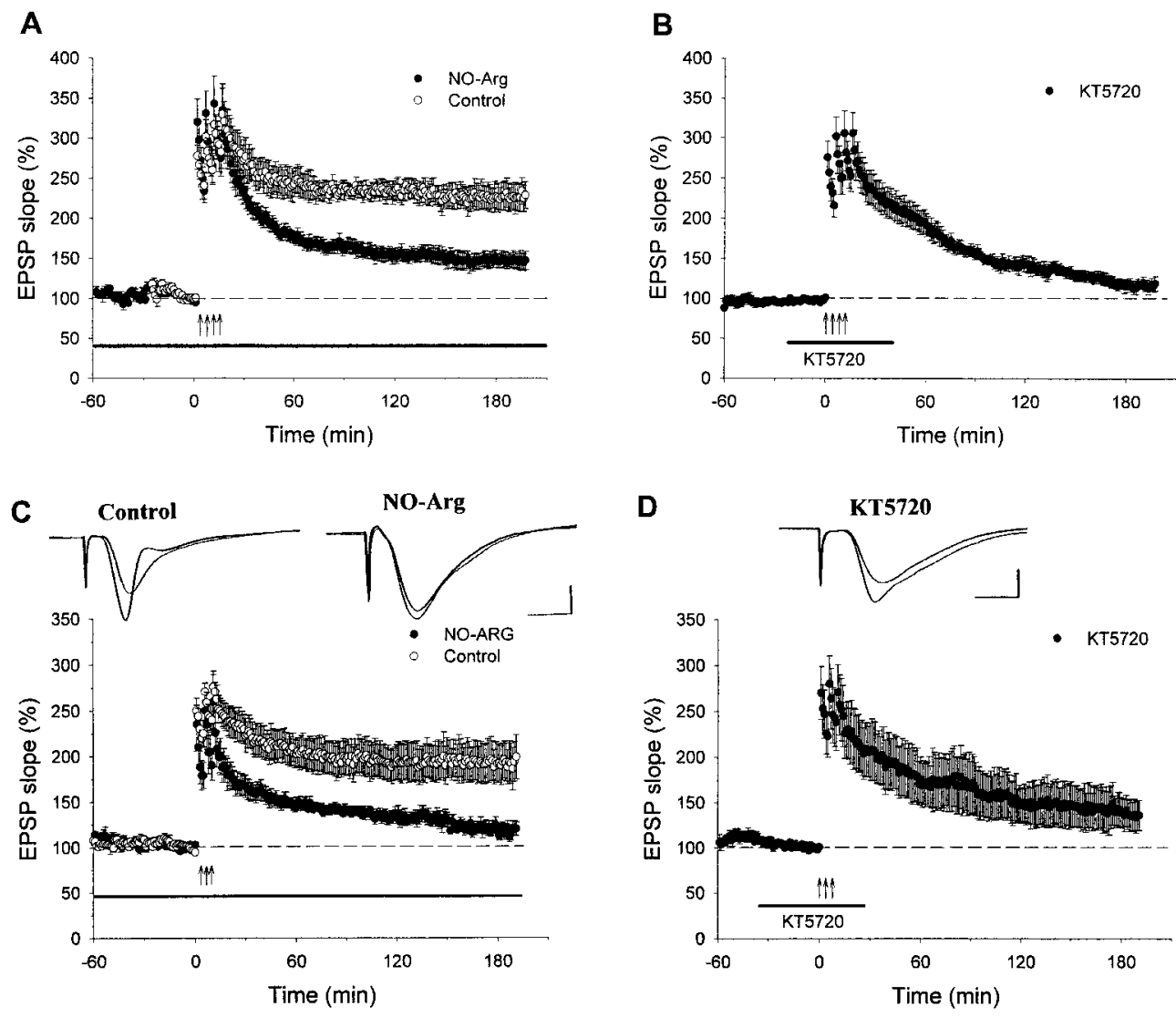

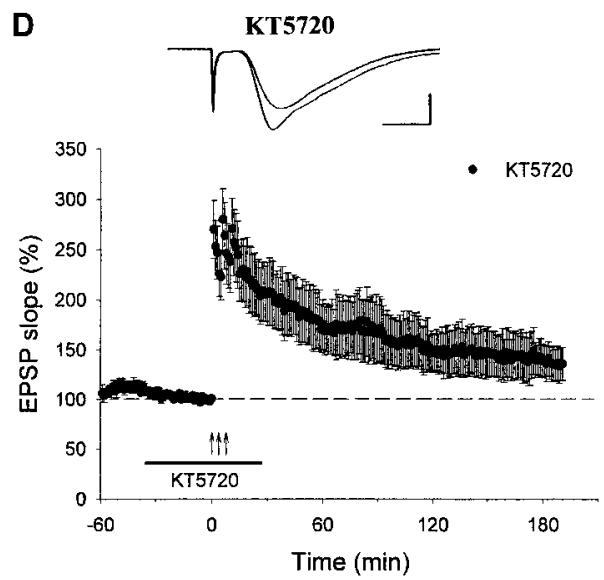

anization, suggest that NO signaling is involved in the formation of L-LTP.

NO induces early-phase potentiation only when it is paired with weak tetanic stimulation, and the potentiation is restricted to the tetanized pathway (Zhuo et al., 1993). To test whether this is also the case for late-phase potentiation, we performed experiments with two independent input pathways to the same group of CA1 pyramidal cells. One-train tetanic stimulation was delivered to one pathway while NO solution was applied to the slice. No tetanization was applied to the second pathway. In the untetanized pathway there were no detectable changes of EPSP slope (99 $\pm 7 \% ; n=4)$, whereas the tetanized pathway showed a significant enhancement of synaptic transmission $[184 \pm 17 \% 3 \mathrm{hr}$ after tetanus; $n=4 ; t(3)=4.94 ; p<0.02 ; t(3)=4.62 ; p<0.05$ compared with the control pathway; Fig. $2 B$ ]. These results show that, as in early-phase potentiation, late-phase potentiation by NO paired with tetanic stimulation is restricted to the tetanized pathway, and $\mathrm{NO}$ alone produces no potentiation.

\section{cGMP is involved in L-LTP}

Because NO is thought to produce early-phase potentiation in part by activating soluble guanylyl cyclase (East and Garthwaite, 1991; Zhuo et al., 1994; Arancio et al., 1995; Boulton et al., 1995; Son et al., 1998), we tested the possible involvement of cGMP in L-LTP. We first examined the effect of ODQ, a specific inhibitor of soluble guanylyl cyclase (Garthwaite et al., 1995), on L-LTP induced by three-train tetanization. ODQ $(5 \mu \mathrm{M})$ applied to the slice at least $60 \mathrm{~min}$ before tetanization and throughout the experiment blocked late-phase potentiation induced by threetrain tetanization $[111 \pm 14 \% 3 \mathrm{hr}$ after tetanization; $n=4$; $t(8)=2.90 ; p<0.05$ compared with normal saline; Fig. $3 A]$. ODQ also blocked late-phase potentiation by NO paired with one-train tetanization $[109 \pm 14 \%$ at $3 \mathrm{hr} ; n=4 ; t(6)=3.11 ; p<0.05$ compared with NO paired with one-train tetanization in normal saline; Fig. 3B]. These results suggest that guanylyl cyclase is involved in NO-induced late-phase potentiation.

Because NO-induced potentiation is thought to be produced in part by activation of guanylyl cyclase resulting in the production of cGMP, we predicted that exogenous application of cGMP analogs should produce the same effect as NO. We tested this idea by using 8-Br-cGMP, a membrane-permeable cGMP analog that is resistant to degradation by phosphodiesterases. We used a low concentration of 8 -Br-cGMP $(1 \mu \mathrm{M})$ that should specifically activate cGMP-dependent protein kinase (PKG) but not PKA because the $K_{a}$ of 8-Br-cGMP is $0.01-0.21 \mu \mathrm{M}$ for PKG and $12 \mu \mathrm{M}$ for PKA (Butt et al., 1992; Sekhar et al., 1992). Perfusion with 8-Br-cGMP for $10 \mathrm{~min}$ before a one-train tetanus produced robust late-phase potentiation $[180 \pm 18 \%$ at $3 \mathrm{hr} ; n=9 ; t(8)=$ 4.44; $p<0.01 ; t(12)=2.62 ; p<0.05$ compared with perfusion with normal saline; Fig. $3 C$ ]. Perfusing the slice with 8-Br-cGMP alone had no effect on the baseline EPSP $(92 \pm 8 \%$ at $3 \mathrm{hr} ; n=$ 3). We also tested 8-pCPT-cGMP, another cGMP analog that has greater membrane permeability and is also more selective for stimulating $\mathrm{PKG}$ as opposed to other cGMP targets such as cGMP-stimulated phosphodiesterases (Geiger et al., 1992). The $K_{a}$ of 8-pCPT-cGMP is $0.04-0.44 \mu \mathrm{M}$ for PKG and $7.0 \mu \mathrm{M}$ for PKA (Butt et al., 1992; Sekhar et al., 1992). 8-pCPT-cGMP (1 $\mu \mathrm{M})$ paired with a one-train tetanus produced robust late-phase potentiation [208 $\pm 13 \%$ at $3 \mathrm{hr} ; n=3 ; t(2)=8.31 ; p<0.05$ ], whereas 8-pCPT-cGMP alone had no effect on the baseline EPSP (86 $\pm 3 \% ; n=3$; Fig. $3 D)$.

The enhanced potentiation by cGMP analogs paired with onetrain tetanus might simply result from increased depolarization of 

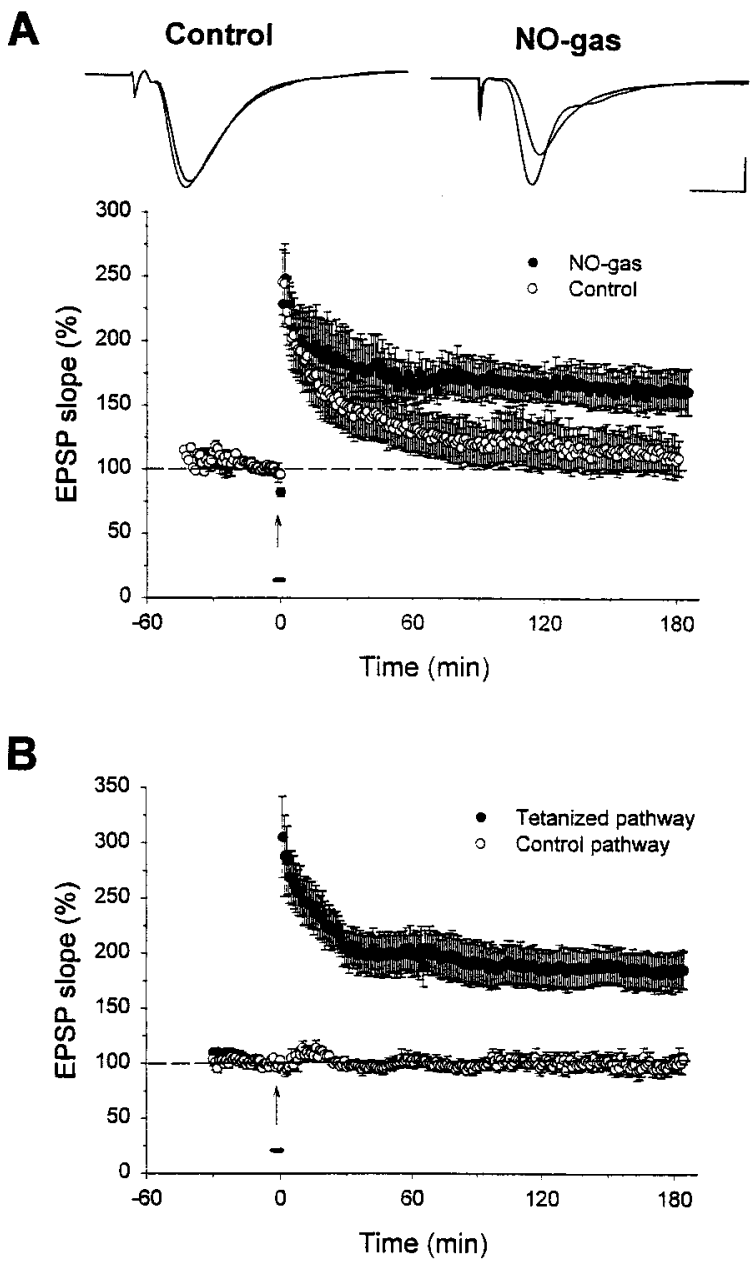

Figure 2. NO produces activity-dependent late-phase potentiation. $A$, NO solution paired with one-train $(100 \mathrm{~Hz} / 1 \mathrm{sec})$ tetanization produced late-phase potentiation, whereas one-train tetanus alone induced only early-phase potentiation. Insets, Representative field EPSPs before and 3 hr after the tetanus are shown. Calibration: $5 \mathrm{msec}, 1 \mathrm{mV}$. $B$, NO paired with one-train tetanus induced late-phase potentiation in the tetanized pathway but not in an untetanized control pathway in the same slice. The two pathways were stimulated alternately.

the postsynaptic cells during the tetanus, perhaps because of disinhibition of GABAergic interneurons (Wexler et al., 1998). However, Son et al. (1998) found no effect of 8-Br-cGMP on the field EPSP during tetanic stimulation. As another way to examine this possibility, we tested the effect of 8-Br-cGMP during blockade of GABAergic inhibition. In the presence of the GABA antagonist picrotoxin $(100 \mu \mathrm{M}), 8$-Br-cGMP paired with onetrain tetanization still produced late-phase potentiation $[176 \pm$ $5 \%$ at $3 \mathrm{hr} ; n=3 ; t(2)=15.20 ; p<0.01]$. Picrotoxin itself had no detectable effect on potentiation induced by one-train tetanization $(109 \pm 8 \%$ at $3 \mathrm{hr} ; n=3)$.

If late-phase potentiation induced by cGMP analogs paired with one-train tetanization shares mechanisms with L-LTP induced by three-train tetanization, potentiation induced by one protocol should occlude potentiation induced by the other. We found that after potentiation produced by 8 -Br-cGMP paired with one-train tetanization, three-train tetanization no longer induced L-LTP $[100 \pm 2 \% 3 \mathrm{hr}$ after three-train tetanization; $n=$ $4 ; t(8)=3.47 ; p<0.01$ compared with normal L-LTP; Fig. $3 E$ ].

\section{PKG is involved in L-LTP}

PKG is thought to be a signaling target by which cGMP contributes to the formation of E-LTP in the hippocampus (Zhuo et al., 1994; Arancio et al., 1995; Blitzer et al., 1995; Son et al., 1998; O. Arancio, I. Antonova, S. Gambaryan, S. M. Lohmann, J. S. Wood, D. S. Lawrence, and R. D. Hawkins, unpublished observations). However, cGMP may also activate other signaling pathways. For example, cyclic nucleotide-gated calcium channels and cGMP-activated phosphodiesterases are also expressed in hippocampal pyramidal cells (Repaske et al., 1993; Kingston et al., 1996; Bradley et al., 1997). Therefore, we examined the effects of PKG inhibitors on L-LTP induced by three-train tetanization. Preincubation with Rp-8-Br-PET-cGMPS (1 $\mu \mathrm{M})$, a selective PKG inhibitor $\left(K_{i}\right.$ of $0.03-0.035 \mu \mathrm{M}$ for $\mathrm{PKG}$ and $11 \mu \mathrm{M}$ for PKA), blocked three-train L-LTP [107 $\pm 11 \%$ at $3 \mathrm{hr} ; n=3$; $t(7)=2.76 ; p<0.05$ compared with normal saline; Fig. $4 A]$. KT5823 $(2 \mu \mathrm{M})$, another structurally different PKG inhibitor $\left(K_{i}\right.$ of $0.234 \mu \mathrm{M}$ for PKG and $>10 \mu \mathrm{M}$ for PKA), produced a similar blockade of L-LTP induced by three-train tetanization [120 \pm $3 \%$ at $3 \mathrm{hr} ; n=3 ; t(7)=2.40 ; p<0.05$ compared with normal saline; Fig. $4 A$ ]. Like the nitric oxide synthase inhibitor NO-Arg (Fig. 1), Rp-8-Br-PET-cGMPS partially reduced four-train L-LTP but did not completely block it $(160 \pm 14 \%$ at $3 \mathrm{hr} ; n=$ 4; Fig. 4B).

Our results suggest that the NO-cGMP-PKG-signaling pathway is involved in three-train L-LTP and to a lesser extent in four-train L-LTP. To examine further whether PKG is a downstream target of cGMP, we tested the effect of a PKG inhibitor on late-phase potentiation induced by a cGMP analog. Perfusion with KT5823 $(2 \mu \mathrm{M})$ for 30 min blocked potentiation by $8-\mathrm{Br}-$ cGMP paired with a one-train tetanus $[107 \pm 14 \%$ at $3 \mathrm{hr} ; n=4$; $t(11)=2.39 ; p<0.05$ compared with normal saline; Fig. $4 C]$. Therefore, PKG seems to be involved in cGMP-induced latephase potentiation.

\section{cGMP-induced late-phase potentiation is dependent on protein and RNA synthesis}

Previous studies have shown that L-LTP produced by multipletrain tetanization requires protein and RNA synthesis (Frey et al., 1988; Huang and Kandel, 1994; Nguyen et al., 1994; Huang et al., 1996). Because late-phase potentiation induced by cGMP analogs shares some common mechanisms with L-LTP induced by three-train tetanization, it was interesting to know whether cGMP-induced late-phase potentiation is also protein and RNA synthesis dependent. Replicating previous results (Huang and Kandel, 1994), we found that L-LTP induced by three-train tetanization was blocked by preincubation with the translational inhibitor anisomycin $(30 \mu \mathrm{M})$ for $30 \min [128 \pm 5 \% ; n=4 ; t(8)=$ 2.47; $p<0.05$ compared with normal saline]. Similarly, after perfusion with anisomycin, 8-Br-cGMP paired with one-train tetanization produced fairly normal early-phase potentiation $(152 \pm 10 \%$ at $1 \mathrm{hr})$ but reduced late-phase potentiation [123 \pm $8 \%$ at $3 \mathrm{hr} ; n=7 ; t(14)=2.46 ; p<0.05$ compared with normal saline; Fig. 5A]. Anisomycin had no effect on the baseline EPSP (95 $\pm 12 \%$ at $3 \mathrm{hr} ; n=2)$. Although anisomycin could have additional molecular actions, these results suggest that late-phase potentiation induced by cGMP is dependent on protein synthesis.

If protein synthesis is required for the expression of late-phase potentiation, the synthesis might occur in the soma of the neurons, but it could also occur at the synapses. For example, in Aplysia some of the new protein necessary for long-term facilitation was found to be synthesized at the synapses by local mRNA 

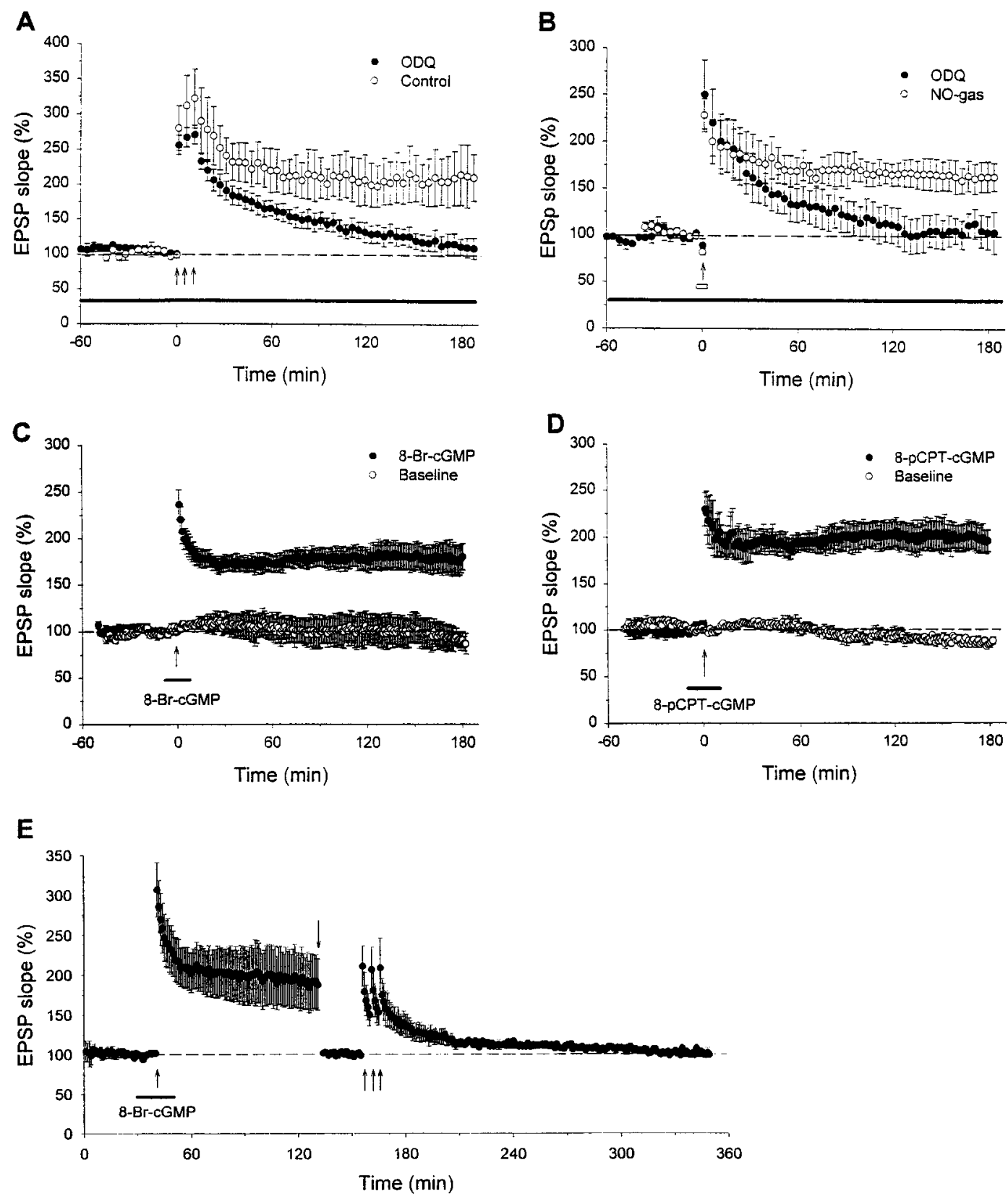

Figure 3. Guanylyl cyclase and cGMP are involved in L-LTP. A, L-LTP induced by three-train tetanization was blocked by the guanylyl cyclase inhibitor ODQ $(5 \mu \mathrm{M})$. ODQ was added to the perfusion solution at least $1 \mathrm{hr}$ before the tetanization and throughout the experiment. $B$, Late-phase potentiation induced by NO solution paired with one-train tetanus was also blocked by ODQ. $C, D$, The cGMP analogs 8 -Br-cGMP (1 $\mu \mathrm{M})$ or 8 -pCPT-cGMP (1 $\mu \mathrm{M})$ paired with one-train tetanus produced late-phase potentiation. 8-Br-cGMP or 8-pCPT-cGMP alone had no effect on the baseline EPSP. The drugs were applied starting 10 min before the tetanus until 10 min after the tetanus. $E$, Potentiation by 8 -Br-cGMP $(1 \mu \mathrm{M})$ paired with one-train tetanization occluded L-LTP by three-train tetanization. Ninety minutes after 8-Br-cGMP-induced potentiation, the stimulation intensity was reduced to reset the baseline to a level similar to that at the beginning of the experiment (downward vertical arrow), and then three-train $100 \mathrm{~Hz} / 1 \mathrm{sec}$ tetanization was delivered.

(Martin et al., 1997a). In the hippocampus, a BDNF-induced enhancement of synaptic transmission was also shown to be dependent on local protein synthesis and was still present after removal of both the pre- and postsynaptic cell bodies (Kang and Schuman, 1996). Therefore, the inhibitory effect of anisomycin may be produced by blockade of the translational mechanism at the cell body and/or synapse. To distinguish between these possibilities and as an additional test of the involvement of macromolecular synthesis, we examined the effect of the transcriptional inhibitor actinomycin D $(40 \mu \mathrm{M})$ and found that it also reduced late-phase potentiation induced by 8 -Br-cGMP paired with onetrain tetanus $[122 \pm 14 \% ; n=6 ; t(13)=2.19 ; p<0.05$ compared with normal saline; Fig. $5 B]$. These results indicate that like L-LTP produced by multiple-train tetanization, cGMP-induced potentiation is protein and RNA synthesis dependent.

Relationship of the PKG- and PKA-signaling pathways in L-LTP

A number of studies have demonstrated the role of PKA in L-LTP (Frey et al., 1993; Huang and Kandel, 1994; Abel et al., 


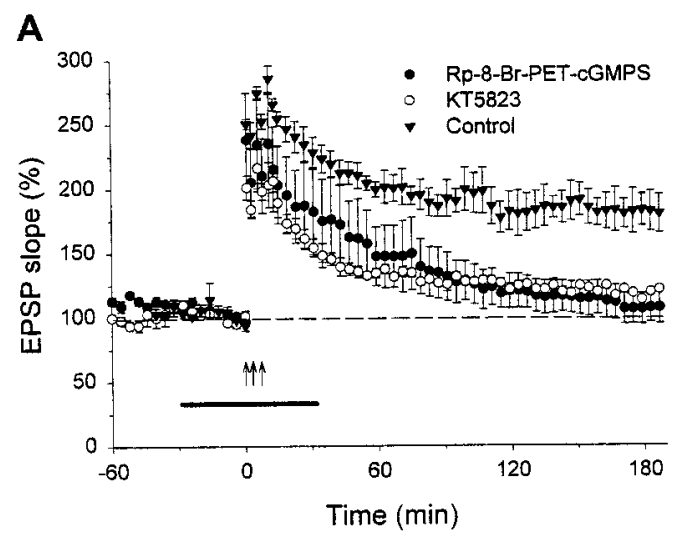

B

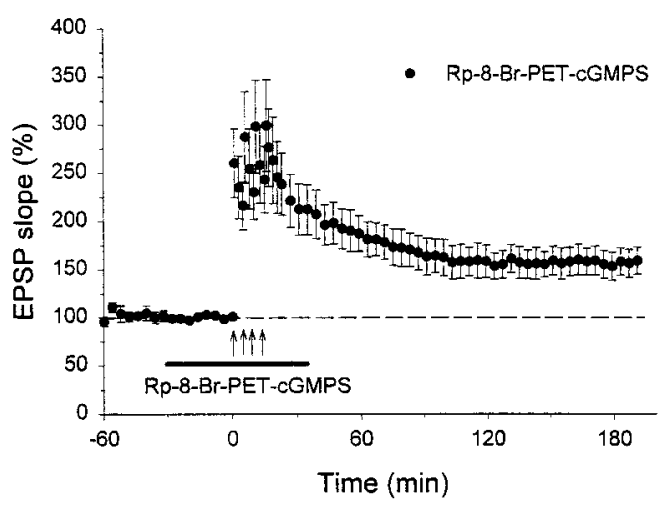

C

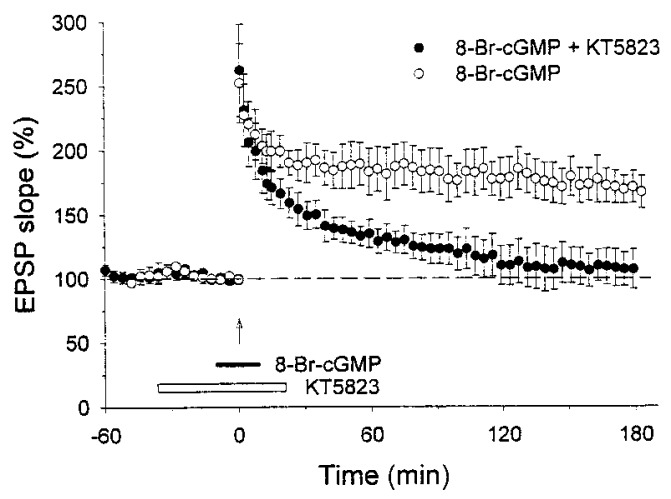

Figure 4. Effect of PKG inhibitors on L-LTP. A, L-LTP induced by three-train tetanization was blocked by the PKG inhibitors KT5823 (2 $\mu \mathrm{M})$ or Rp-8-Br-PET-cGMPS $(1 \mu \mathrm{M})$. The drugs were applied $30 \mathrm{~min}$ before until $20 \mathrm{~min}$ after the tetanus, as indicated by the horizontal bar. B, L-LTP induced by four-train tetanization was reduced but not completely blocked by Rp-8-Br-PET-cGMPS. $C$, Late-phase potentiation induced by 8-Br-cGMP $(1 \mu \mathrm{M})$ paired with one-train tetanization was also blocked by KT5823 $(2 \mu \mathrm{M})$.

1997; Winder et al., 1998). In the present study we have shown that the PKG-signaling pathway also appears to be involved in L-LTP by using cGMP analogs (8-Br-cGMP and 8-pCPTcGMP) and PKG inhibitors (KT5823 and Rp-8-Br-PET-cGMP) at relatively low concentrations that were chosen to selectively affect PKG but not PKA. Therefore, it was interesting to investigate the relationship of PKA and $\mathrm{PKG}$ in the induction of L-LTP.

One possibility is that cGMP and PKG produce late-phase potentiation by stimulating PKA. Consistent with this possibility,
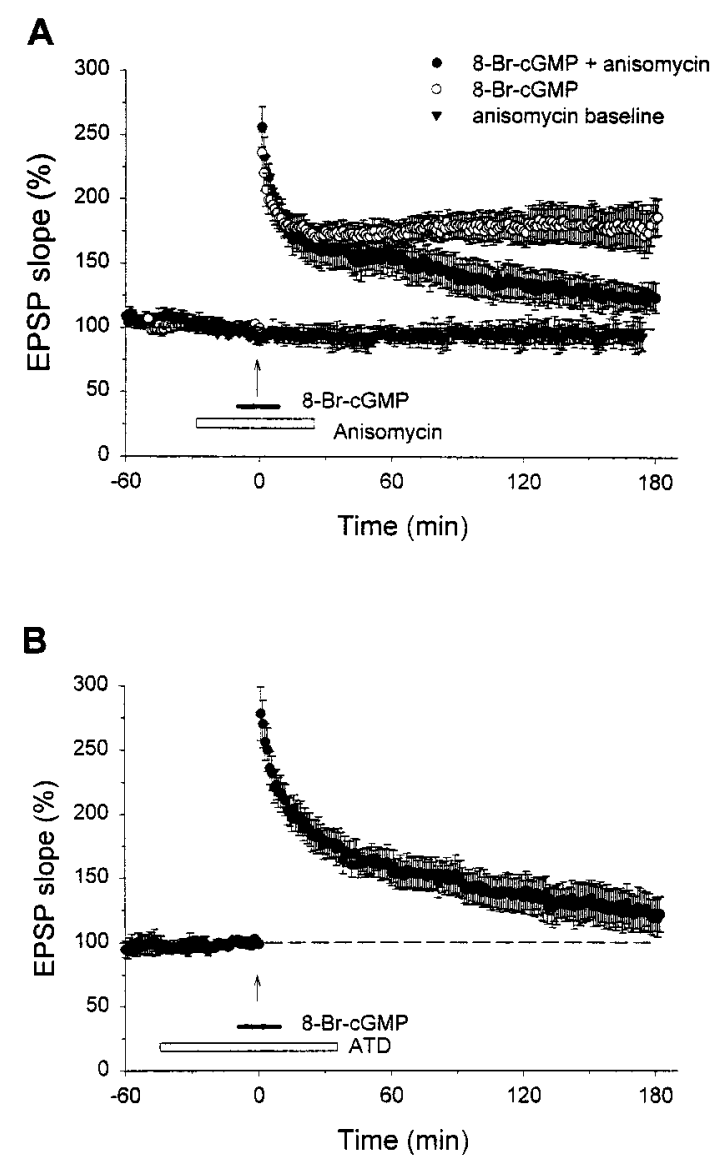

Figure 5. cGMP analog-induced late-phase potentiation is dependent on macromolecular synthesis. $A$, Late-phase potentiation induced by $8-\mathrm{Br}-$ cGMP $(1 \mu \mathrm{M})$ paired with one-train tetanization was blocked by the protein synthesis inhibitor anisomycin $(30 \mu \mathrm{M})$, whereas the baseline EPSP was not affected by anisomycin. Anisomycin was applied from 30 min before until $25 \mathrm{~min}$ after the tetanus. $B$, Late-phase potentiation induced by 8 -Br-cGMP $(1 \mu \mathrm{M})$ paired with one-train tetanization was also blocked by the transcriptional inhibitor actinomycin D $(A T D ; 40 \mu \mathrm{M})$. Actinomycin D was applied from $30 \mathrm{~min}$ before until $25 \mathrm{~min}$ after the tetanus.

the type 1 regulatory subunit of PKA (PKAR1) is a substrate for PKG (Geahlen and Krebs, 1980), and phosphorylation of PKAR1 by PKG results in loss of inhibition of the catalytic subunit of PKA in vitro, although it is not clear whether this also happens in vivo (Geahlen et al., 1981). However, the finding that PKG and PKA are preferentially involved in three- and four-train L-LTP, respectively (Figs. 1, 4), argues against this possibility. As an additional test of this idea, we examined the effect of a PKA inhibitor on cGMP-induced potentiation. Preincubation with the PKA inhibitor KT5720 $(1 \mu \mathrm{M})$ produced only a small reduction of late-phase potentiation by 8 -Br-cGMP paired with one-train tetanus $(158 \pm 11 \% ; n=3$; Fig. $6 A)$. This result suggests that cGMP does not act by stimulating PKA during the induction of L-LTP. As a positive control for the effectiveness of the drug, we found that the same concentration of KT5720 (1 $\mu \mathrm{M})$ completely blocked the long-lasting potentiation of synaptic transmission produced by the PKA agonist Sp-cAMPS (100 $\mu \mathrm{M})$ (Fig. $6 B)$.

If $\mathrm{PKG}$ and $\mathrm{PKA}$ activate independent pathways initially but converge at some later step during the induction of L-LTP, activating one pathway should occlude potentiation induced by the other pathway. To test this possibility, we first applied the 


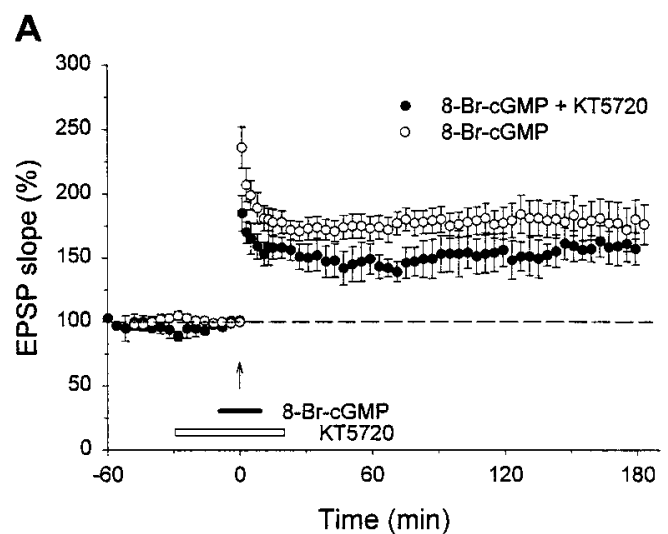

B
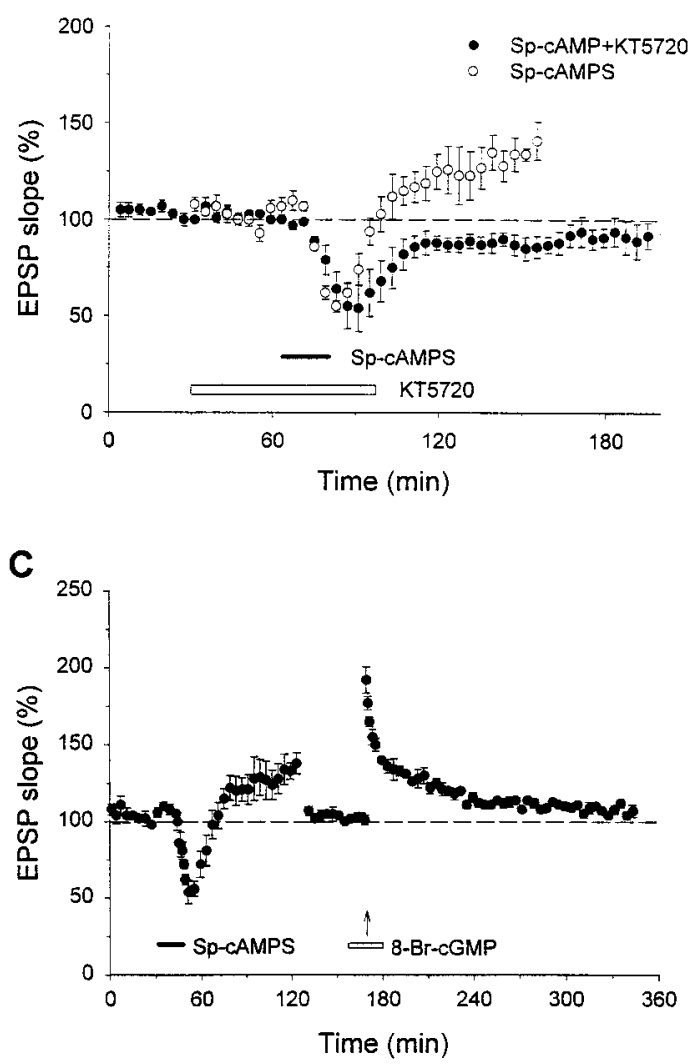

Figure 6. Relationship between PKG and PKA in the induction of late-phase potentiation. $A$, Late-phase potentiation induced by $8-\mathrm{Br}$ cGMP paired with one-train tetanization was not significantly reduced by the PKA inhibitor KT5720 (1 $\mu \mathrm{M})$. KT5720 was applied from $30 \mathrm{~min}$ before until $20 \mathrm{~min}$ after the tetanus. B, KT5720 $(1 \mu \mathrm{M})$ blocked enhancement of synaptic transmission by the PKA activator Sp-cAMPS (100 $\mu \mathrm{M})$. $C$, Potentiation induced by Sp-cAMPS $(100 \mu \mathrm{M})$ occluded late-phase potentiation by 8 -Br-cGMP paired with one-train tetanus. Ninety minutes after Sp-cAMPS-induced potentiation, the stimulation intensity was reduced to obtain a new baseline similar to that at the beginning of the experiment, and then 8-Br-cGMP was applied paired with one-train tetanus.

PKA activator Sp-cAMPS $(100 \mu \mathrm{M})$ for $15 \mathrm{~min}$. In agreement with previous studies (Frey et al., 1993; Nguyen et al., 1994; Winder et al., 1998), Sp-cAMPS produced inhibition during the application, followed by long-lasting potentiation after washout of the drug $[135 \pm 5 \% 90 \mathrm{~min}$ after application of Sp-cAMPS; $n=$ $3 ; t(2)=7.00 ; p<.05$; Fig. $6 C]$. The test stimulation intensity was then reduced to obtain a new baseline similar to that before Sp-cAMPS application. Under this condition, 8-Br-cGMP paired with one-train tetanization induced early-phase potentiation but no late-phase potentiation $[106 \pm 3 \% 3 \mathrm{hr}$ after the tetanus; $n=$ $3 ; t(10)=2.57 ; p<0.05$ compared with normal 8-Br-cGMPinduced potentiation]. This result suggests that PKG and PKA share some common downstream mechanism during the induction of L-LTP.

Together with the finding that a PKA inhibitor did not block cGMP-induced potentiation, these results suggest that PKG and PKA activate independent pathways initially, but their signaling pathways merge at some later step. The evidence that both PKGand PKA-induced late-phase potentiation are blocked by inhibitors of protein and RNA synthesis (Fig. 5) (Frey et al., 1993) also suggests that they might share some of the same mechanisms.

\section{cGMP-induced late-phase potentiation is accompanied by CREB phosphorylation}

The late, protein synthesis-dependent phase of LTP is thought to involve induction of immediate early genes via phosphorylation of CREB, mediated in part via PKA (Bourtchouladze et al., 1994; Impey et al., 1996, 1998; Matthies et al., 1997; Gass et al., 1998). Previous studies in other systems have shown that NO is also involved in gene expression associated with activation of CREB (Peunova and Enlkolopov, 1993; Ohki et al., 1995; Ding et al., 1997) and that cGMP and PKG can trigger gene induction via CREB phosphorylation (Haby et al., 1994; Gudi et al., 1996, 1997). We therefore investigated whether PKG might also cause CREB phosphorylation during the induction of late-phase potentiation by examining phospho-CREB immunofluorescence in hippocampal slices that had received the same treatments described in the electrophysiological experiments. The slices were fixed either 1 or 60 min after the treatments, stained with an antibody for CREB phosphorylated at Ser-133, and viewed on a confocal microscope.

We first examined phospho-CREB immunofluorescence after either four- or three-train tetanization (Fig. 7). One minute after the end of four-train tetanization, the intensity of immunofluorescence in the CA1 cell body area was significantly increased compared with that in untreated control slices from the same animals [187 $\pm 12 \%$ of control; $\left.n=7 ; F_{(1,71)}=93.63 ; p<0.01\right]$. The increase in phospho-CREB immunofluorescence was almost completely blocked by an inhibitor of PKA, KT5720 [112 $\pm 7 \%$; $n=7 ; F_{(1,71)}=35.15 ; p<0.01$ compared with no inhibitor], and was also significantly reduced but not completely blocked by an inhibitor of PKG, KT5823 [132 $\pm 8 \% ; n=7 ; F_{(1,71)}=12.33 ; p<$ 0.01 compared with control; $F_{(1,71)}=19.00 ; p<0.01$ compared with no inhibitor]. One minute after the end of three-train tetanization, there was also a significant increase in phospho-CREB immunofluorescence that was somewhat smaller than that after four-train tetanization $\left[148 \pm 8 \% ; n=8 ; F_{(1,71)}=32.96 ; p<0.01\right.$ compared with control; $F_{(1,71)}=9.89 ; p<0.01$ compared with four-train]. However, unlike the increase in immunofluorescence after four-train tetanization, the increase after three-train tetanization was not reduced by an inhibitor of PKA, KT5720 (156 \pm $5 \% ; n=6)$, but it was almost completely blocked by an inhibitor of PKG, KT5823 [112 $\pm 5 \% ; n=6 ; F_{(1,71)}=8.16 ; p<0.01$ compared with no inhibitor]. Thus, like L-LTP by three- and four-train tetanization (Figs. 1, 4), the increases in immunofluorescence after three- and four-train tetanization were affected differently by inhibitors of PKA and PKG [drug $\times$ train number interaction, $\left.F_{(1,22)}=18.78 ; p<0.01\right]$. These results suggest that 


\section{A}

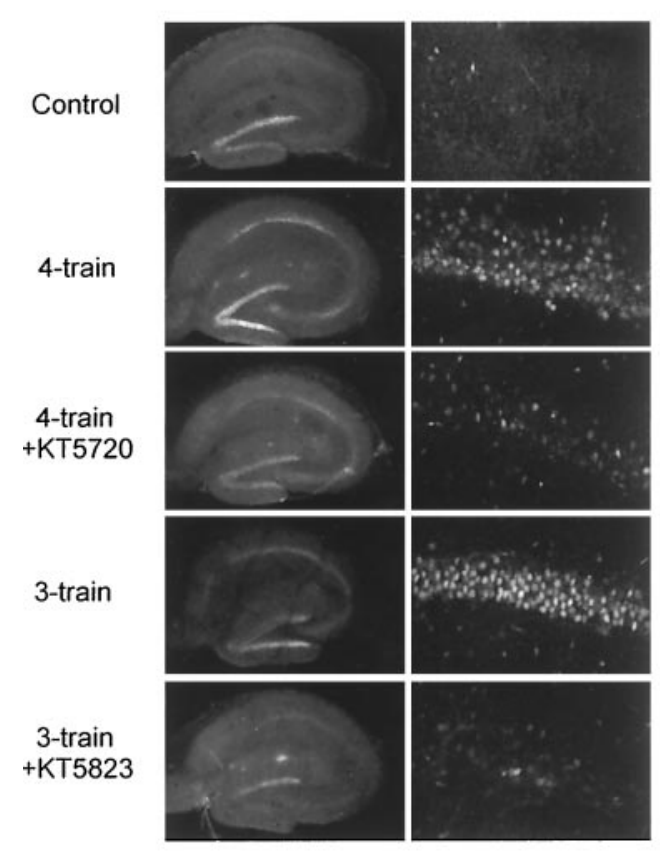

B
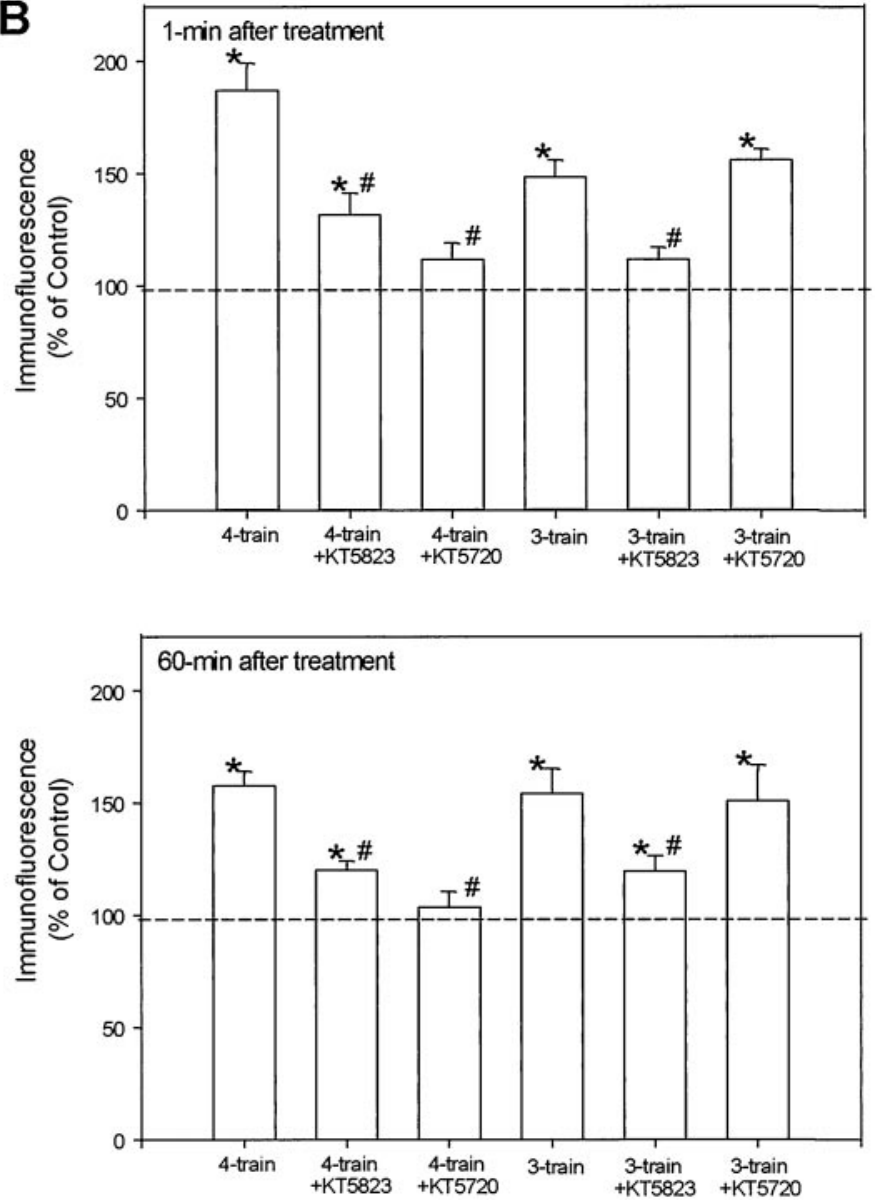

Figure 7. Increase in phospho-CREB immunofluorescence after three- or four-train tetanization. $A$, Representative examples of hippocampal slices stained with a phospho-CREB antibody. The slices were fixed 1 min after either no treatment (Control), four-train tetanization of the Schaffer collateral pathway, four-train tetanization during perfusion with the PKA inhibitor KT5720, three-train tetanization, or three-train tetanization during perfusion with the PKG inhibitor KT5823. Left, Low-power $(5 \times$ objective) view of the entire slice. Right, Higher power $(40 \times$ objective) view of the CA1 cell body area. $B$, Average immunofluorescence intensity in the CA1 cell body area, compared with untreated control slices from the same animals. Top, Slices fixed 1 min after tetanization. Bottom, Slices fixed 60 min after tetanization. The data are expressed as mean ( \pm SEM) percent of control. There was a significant effect of group $\left[F_{(5,71)}=15.29 ; p<0.01\right]$ in a two-way ANOVA (group and time). In subsequent planned comparisons, ${ }^{*} p<0.05$ compared with control slices; $\# p<0.05$ compared with slices with no inhibitor.

PKA and PKG contribute preferentially to somewhat different components of CREB phosphorylation, with PKA contributing more importantly than $\mathrm{PKG}$ with four-train tetanization and PKG contributing more importantly than PKA with three-train tetanization.

The similarity between the results on phospho-CREB immunofluorescence and L-LTP supports the idea that CREB phosphorylation is a key step in the induction of the potentiation. However, there was one case in which the two sets of results were not parallel: with three-train tetanization, an inhibitor of PKA significantly reduced L-LTP (Fig. $1 D$ ) but had no effect on the increase in phospho-CREB immunofluorescence. This result suggests that PKA may play some role in L-LTP in addition to CREB phosphorylation, perhaps by acting on another transcription factor or a coactivator necessary for transcription.

Sixty minutes after these treatments CREB phosphorylation was very similar to that seen 1 min after the treatments, with one exception: the increase in immunofluorescence after four-train tetanization was significantly less at $60 \mathrm{~min}$ than at $1 \mathrm{~min}[158 \pm$ $7 \% ; n=7 ; F_{(1,71)}=5.26 ; p<0.05$ compared with $\left.1 \mathrm{~min}\right]$, although it was still significantly greater than control $\left[F_{(1,71)}=\right.$ 41.37; $p<0.01]$. There was no such decline in phospho-CREB immunofluorescence after three-train tetanization, suggesting that these two different training protocols may also produce temporally different patterns of CREB phosphorylation.

We next examined phospho-CREB immunofluorescence after treatments with cyclic nucleotide analogs (Fig. 8). There was a significant increase in immunofluorescence 1 min after treatment with 8-Br-cGMP paired with 1 train tetanization [169 $\pm 14 \%$; $\left.n=7 ; F_{(1,115)}=44.76 ; p<0.01\right]$. By contrast, there was no significant change in immunofluorescence after treatment with one-train tetanization alone $(97 \pm 8 \% ; n=6)$ or 8 -Br-cGMP alone $(109 \pm 6 \% ; n=9)$. The increase in immunofluorescence by 8-Br-cGMP paired with one-train tetanization was significantly reduced by an inhibitor of PKG, KT5823 [104 $\pm 8 \% ; n=7$; $F_{(1,115)}=19.77 ; p<0.01$ compared with no inhibitor], but not by an inhibitor of PKA, KT5720 $(179 \pm 11 \% ; n=8)$. There was also a significant increase in immunofluorescence $1 \mathrm{~min}$ after treatment with the cAMP analog Sp-cAMPS $[213 \pm 25 \% ; n=6$; $\left.F_{(1,115)}=101.03 ; p<0.01\right]$ that was significantly reduced by the 

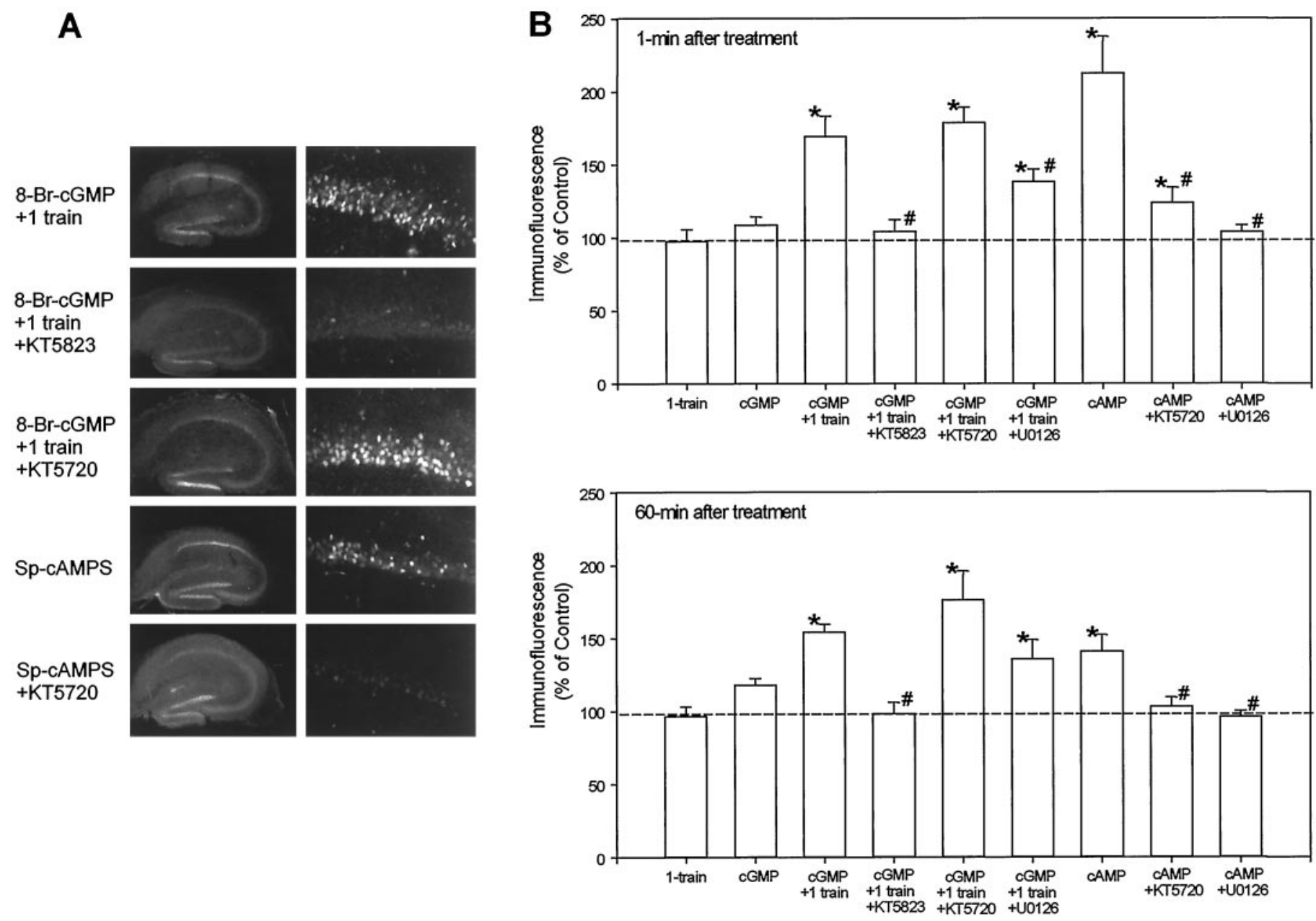

Figure 8. Increase in phospho-CREB immunofluorescence after treatment with cyclic nucleotide analogs. A, Representative examples of phosphoCREB immunofluorescence in slices that were fixed 1 min after treatment with either 8-Br-cGMP paired with one-train tetanization, 8-Br-cGMP paired with one-train tetanus during perfusion with the PKG inhibitor KT5823, 8-Br-cGMP paired with one-train tetanus during perfusion with the PKA inhibitor KT5720, Sp-cAMPS, or Sp-cAMPS during perfusion with KT5720. B, Average immunofluorescence intensity in the CA1 cell body area, compared with untreated control slices. There were significant effects of group $\left[F_{(8,115)}=20.61 ; p<0.01\right]$, time $\left[F_{(1,115)}=7.15 ; p<0.01\right]$, and the group $\times$ time interaction $\left[F_{(8,15)}=2.59 ; p<0.05\right]$ in a two-way ANOVA. Perfusion with the MAP kinase inhibitor U0126 (20 $\left.\mu \mathrm{M}\right)$ began 60 min before and ended 20 min after perfusion with the cyclic nucleotide analogs.

PKA inhibitor KT5720 $\left[124 \pm 10 \% ; n=6 ; F_{(1,115)}=31.34 ; p<\right.$ 0.01 compared with no inhibitor]. In all of these cases the results on CREB phosphorylation were similar to the electrophysiological results on late-phase potentiation (Figs. $4 C, 6 A, B$ ) and support the idea that PKG and PKA act in parallel to phosphorylate CREB during the induction of L-LTP.

Recent evidence indicates that MAP kinase also plays an important role in late-phase potentiation and CREB phosphorylation (English and Sweatt, 1997; Atkins et al., 1998; Impey et al., 1998) and that cAMP and PKA may act in part by activating MAP kinase (Martin et al., 1997b; Impey et al., 1998; Michael et al., 1998). Consistent with that idea, the increase in phosphoCREB immunofluorescence by Sp-cAMPS was almost completely blocked by an inhibitor of MAP kinase, U0126 [104 $\pm 2 \%$; $n=9 ; F_{(1,115)}=56.47 ; p<0.01$ compared with no inhibitor], as well as by the PKA inhibitor KT5720. We therefore investigated whether cGMP-induced CREB phosphorylation also involves MAP kinase. The increase in immunofluorescence by $8-\mathrm{Br}-$ cGMP paired with one-train tetanization was significantly reduced but not completely blocked by the MAP kinase inhibitor
$\mathrm{U} 0126\left[138 \pm 8 \% ; n=8 ; F_{(1,115)}=15.67 ; p<0.01\right.$ compared with control; $F_{(1,115)}=4.76 ; p<0.05$ compared with no inhibitor]. These results suggest that cGMP may cause CREB phosphorylation in part via MAP kinase but that it can also cause CREB phosphorylation independent of both MAP kinase and PKA.

Sixty minutes after these treatments CREB phosphorylation was very similar to that seen 1 min after the treatments, with one exception: the increase in phospho-CREB immunofluorescence after treatment with Sp-cAMPS was significantly less at $60 \mathrm{~min}$ than at $1 \min \left[141 \pm 11 \% ; n=7 ; F_{(1,115)}=22.01 ; p<0.01\right.$ compared with $1 \mathrm{~min}]$, although it was still significantly greater than control $\left[F_{(1,115)}=15.61 ; p<0.01\right]$. There was no such decline in phospho-CREB immunofluorescence after 8-BrcGMP paired with one-train tetanization [drug $\times$ time interaction, $\left.F_{(1,28)}=4.48 ; p<0.05\right]$. These results suggest that the cGMP-dependent component of late-phase potentiation involves phosphorylation of CREB that is stable for at least $1 \mathrm{hr}$ after treatment, whereas the cAMP-dependent component involves more transient phosphorylation of CREB. We obtained a similar pattern of results with three- and four-train tetanization, respec- 
tively (Fig. 7), consistent with the idea that four-train tetanization recruits the cAMP-dependent component relatively more strongly.

\section{DISCUSSION}

\section{The NO-cGMP-PKG-signaling pathway and PKA both contribute to L-LTP}

NO signaling is thought to be involved in E-LTP that is induced by one or two trains of tetanic stimulation and lasts $\sim 1 \mathrm{hr}$ (for review, see Hawkins et al., 1998). By contrast, PKA is not thought to be involved in E-LTP induced by one-train tetanic stimulation (Huang and Kandel, 1994; Huang et al., 1996), although recent evidence indicates that PKA does make a contribution to a novel, intermediate phase of LTP that can be produced by two tetani and does not depend on protein synthesis (Blitzer et al., 1995, 1998; Winder et al., 1998) as well as to L-LTP that is induced by three or four tetani and is protein synthesis dependent (Frey et al., 1993; Huang and Kandel, 1994; Huang et al., 1996; Abel et al., 1997; Winder et al., 1998). In the present study we found that NO and PKG also contribute to L-LTP induced by three-train tetanization and to a lesser extent to L-LTP induced by four-train tetanization, whereas PKA contributes more to four-train L-LTP than to three-train L-LTP. Taken together, these results indicate that PKG and PKA are both involved in L-LTP induced by multiple trains of tetanic stimulation. However, the contribution of PKG evidently declines as that of PKA grows with increasing numbers of tetani, suggesting that PKG and PKA play somewhat complementary roles in LTP.

The idea that different molecular mechanisms make different contributions to LTP depending on the protocol may help to explain some of the conflicting results on the roles of NO, cGMP, and PKG in E-LTP. A number of studies have supported the involvement of the NO-cGMP-PKG-signaling pathway in E-LTP, but other studies have found either that those molecules are not involved or that they are involved with some protocols but not others (for review, see Hawkins et al., 1998). For example, one recent study found no effect on E-LTP of a double knock-out of two isoforms of PKG (Kleppisch et al., 1999). However, that same study also reported no effect of an inhibitor of soluble guanylyl cyclase, ODQ, whereas previous studies had found that ODQ produced a clear reduction of E-LTP (Boulton et al., 1995; Son et al., 1998). A plausible explanation for these discrepant results is that the NO-cGMP-PKG pathway contributes to LTP but that other, independent mechanisms such as PKA signaling also contribute, and their relative contributions (and thus the experimental results) depend on the experimental protocol. For example, a number of studies have found that NO makes a relatively larger contribution to E-LTP when it is induced by weaker tetanic stimulation (Chetkovich et al., 1993; Haley et al., 1993; O’Dell et al., 1994; Malen and Chapman, 1997; Zhuo et al., 1998; but see Gribkoff and Lum-Ragan, 1992), and we have now extended that finding to L-LTP. Similarly, Son et al. (1998) recently identified experimental variables that affect the contribution of cGMP to E-LTP. Thus, differences in experimental procedures can account for some of the discrepant results on the roles of NO, cGMP, and PKG in LTP.

\section{cGMP and PKG increase CREB phosphorylation in parallel with PKA and MAP kinase}

Our results on phospho-CREB immunofluorescence are consistent with the results of previous studies that have shown that the induction of L-LTP in hippocampal slices is accompanied by an increase in CREB phosphorylation (Impey et al., 1996; Matthies et al., 1997) as well as CRE-mediated gene expression that depends on PKA (Impey et al., 1996). In addition, we have found that cGMP and PKG can also contribute to CREB phosphorylation and that this signaling pathway plays a relatively larger role after three-train tetanization than after four-train tetanization. The increase in CREB phosphorylation by 8 -Br-cGMP paired with one-train tetanization was not blocked by an inhibitor of PKA, indicating that cGMP and PKG do not act by stimulating PKA. The increase in phospho-CREB immunofluorescence was also only partially reduced by an inhibitor of MAP kinase, indicating that cGMP and PKG cause CREB phosphorylation, at least in part, via some other pathway.

One possibility is that PKG may directly phosphorylate CREB at the same site as PKA. PKG can phosphorylate CREB directly in vitro (Colbran et al., 1992) and is thought to act directly in transfected kidney cells (Gudi et al., 1996), but it is not known whether this occurs in neurons. Another possibility is that PKG may phosphorylate CREB indirectly via some other kinase such $\mathrm{Ca}^{2+} /$ calmodulin-dependent kinase $(\mathrm{CamK})$, perhaps by triggering $\mathrm{Ca}^{2+}$ release from intracellular $\mathrm{Ca}^{2+}$ stores. $\mathrm{PKG}$ activates ADP ribosyl cyclase leading to the production of cyclic ADP ribose, which in turn acts synergistically with $\mathrm{Ca}^{2+}$ to stimulate ryanodine receptors and cause release of $\mathrm{Ca}^{2+}$ from intracellular stores (Galione et al., 1993; Lee, 1993). $\mathrm{Ca}^{2+}$ release from intracellular stores has been implicated in the induction of LTP in hippocampal slices (Harvey and Collingridge, 1992; Wang et al., 1996), and CamK is important for CREB phosphorylation during LTP in cultured hippocampal neurons (Bito et al., 1996; Deisseroth et al., 1996, 1998). In agreement with this possibility, in preliminary experiments we have found that both late-phase potentiation and the increase in CREB phosphorylation by $8-\mathrm{Br}-$ cGMP paired with one-train tetanization are blocked by prolonged exposure to ryanodine, which decreases $\mathrm{Ca}^{2+}$ release from ryanodine-sensitive intracellular $\mathrm{Ca}^{2+}$ stores (Y.-F. Lu and R. D. Hawkins, unpublished observations).

\section{Roles of NO, cGMP, and PKG in E-LTP and L-LTP}

The finding that NO, cGMP, and PKG are involved in L-LTP as well as E-LTP raises the question of what (if anything) is the relationship between the roles of these molecules in the different phases of LTP. During E-LTP, NO is thought to act as a retrograde messenger that stimulates cGMP and PKG in the presynaptic terminals. Results from a number of experiments on hippocampal slices are consistent with this hypothesis (for review, see Hawkins et al., 1998), and experiments on dissociated cultures of hippocampal neurons strongly support it (Arancio et al., 1995, 1996) (Arancio, Antonova, Gambaryan, Lohmann, Wood, Lawrence, and Hawkins, unpublished observations). Our results indicate that NO, cGMP, and PKG are also involved in L-LTP that requires protein and RNA synthesis. Although there could be local protein synthesis at the synapses (Kang and Schuman, 1996; Martin et al., 1997a), the RNA synthesis critical for late-phase potentiation probably occurs in the cell bodies. Moreover, it most likely occurs in the postsynaptic neurons because L-LTP is blocked when the dendrites are surgically separated from the postsynaptic cell bodies (Frey et al., 1989), whereas both L-LTP by tetanic stimulation and late-phase potentiation by $\mathrm{NO}$ or cGMP analogs are normal in slices from which the presynaptic cell bodies have been surgically removed (our picrotoxin experiments; Lu and Hawkins, unpublished observations). Furthermore, we have found that late-phase potentiation is accompanied 
by an increase in phospho-CREB immunofluorescence in the postsynaptic (CA1) cell bodies. Thus, NO, cGMP, and PKG may have different sites of action for the different phases of potentiation.

One possibility is that NO generated in the postsynaptic neurons may diffuse not only to the presynaptic terminals to induce E-LTP but also to postsynaptic dendrites or cell bodies to induce protein- and RNA synthesis-dependent L-LTP. An interesting implication of this idea is that NO might also diffuse to neighboring neurons and produce late-phase potentiation in them as well, much as it is thought to for early-phase potentiation (Bonhoeffer et al., 1989; Schuman and Madison, 1994). However, because NO or 8-Br-cGMP must be paired with one-train tetanization to produce either late-phase potentiation or CREB phosphorylation, presumably only neighboring neurons with some minimum level of synaptic activity would undergo the potentiation. This idea is analogous to the idea that NO and activity act synergistically to preserve the pathway specificity of early-phase potentiation by a freely diffusible retrograde messenger molecule (Hawkins et al., 1993).

These arguments suggest that NO may act to produce earlyand late-phase potentiation by two completely independent mechanisms in different cellular locations. However, the finding that the same signaling pathway (NO-cGMP-PKG) appears to be involved in both phases of potentiation suggests that they may be coordinated in some way. One way that early- and late-phase potentiation might interact is via synaptic "tagging." Evidence from both hippocampus and Aplysia suggests that local events that occur during early-phase LTP or facilitation somehow "tag" the active synapses, so that those synapses can use the newly synthesized proteins when they arrive from the cell body for the late phase (Frey and Morris, 1997; Martin et al., 1997a). The finding that NO paired with a single tetanus to one input pathway produces late-phase potentiation in that pathway but not in a control pathway in the same slice (Fig. 2B) suggests that latephase potentiation by NO also involves synaptic tagging. Because Frey and Morris (1997) and we (data not shown) have found that a single tetanus by itself is not sufficient to tag synapses for late-phase potentiation, these results also suggest that the NOsignaling pathway may play some role in local synaptic tagging that could serve to link its other roles in L-LTP and E-LTP.

\section{REFERENCES}

Abel T, Nguyen PV, Barad M, Deuel TAS, Kandel ER, Bourtchouladze R (1997) Genetic demonstration of a role for PKA in the late phase of LTP and in hippocampus-based long-term memory. Cell 88:615-626.

Arancio O, Kandel ER, Hawkins RD (1995) Activity-dependent longterm enhancement of transmitter release by presynaptic $3^{\prime}, 5^{\prime}$-cyclic GMP in cultured hippocampal neurons. Nature 376:74-80.

Arancio O, Kiebler M, Lee CJ, Lev-Ram V, Tsien RY, Kandel ER, Hawkins RD (1996) Nitric oxide acts directly in the presynaptic neuron to produce long-term potentiation in cultured hippocampal neurons. Cell 87:1025-1035.

Atkins CM, Selcher JC, Petraitis JJ, Trzaskos JM, Sweatt JD (1998) The MAPK cascade is regulated for mammalian associative learning. Nat Neurosci 1:602-609.

Bito H, Deisseroth K, Tsien RW (1996) CREB phosphorylation and dephosphorylation: $\mathrm{a} \mathrm{Ca}^{2+}$ and stimulus duration-dependent switch for hippocampal gene expression. Cell 87:1203-1214.

Bliss TVP, Collingridge GL (1993) A synaptic model of memory: longterm potentiation in the hippocampus. Nature 361:31-39.

Blitzer RD, Wong T, Nouranifar R, Iyengar R Landau EM (1995) Postsynaptic cAMP pathway gates early LTP in hippocampal CA1 region. Neuron 15:1403-1414.

Blitzer RD, Connor JH, Brown GP, Wong T, Shenolikar S, Iyengar R,
Landau EM (1998) Gating of CaMKII by cAMP-regulated protein phosphatase activity during LTP. Science 280:1940-1943.

Bohme GA, Bon C, Stutzmann JM, Doble A, Blanchard JC (1991) Possible involvement of nitric oxide in long-term potentiation. Eur J Pharmacol 199:379-381.

Bonhoeffer T, Staiger V, Aertsen A (1989) Synaptic plasticity in rat hippocampal slice cultures: local "Hebbian" conjunction of pre- and postsynaptic stimulation leads to distributed synaptic enhancement. Proc Natl Acad Sci USA 86:8113-8117.

Boulton CL, Southam E, Garthwaite J (1995) Nitric-oxide dependent long-term potentiation is blocked by inhibitors of soluble guanylyl cyclase. Neuroscience 69:699-703.

Bourtchouladze R, Frenguelli B, Blendy J, Cioffi D, Schutz G, Silva AJ (1994) Deficient long-term memory in mice with a targeted mutation of the cAMP-responsive element-binding protein. Cell 79:59-68.

Bradley T, Zhang Y, Bakin R, Lester HA, Ronnett GV, Zin K (1997) Functional expression of the heteromeric "olfactory" cyclic nucleotidegated channel in the hippocampus: a potential effector of synaptic plasticity in brain neurons. J Neurosci 17:1993-2005.

Bredt DS, Snyder SH (1992) Nitric oxide, a novel neuronal messenger. Neuron 8:3-11.

Butt E, Nolte C, Schulz S, Beltman J, Beavo JA, Jastorff B, Walter U (1992) Analysis of the functional role of cGMP-dependent protein kinase in intact human platelets using a specific activator 8-parachlorophenylthio-cGMP. Biochem Pharmacol 43:2591-2600.

Chetkovich DM, Klann E, Sweatt JD (1993) Nitric oxide synthaseindependent long-term potentiation in area CA1 of hippocampus. NeuroReport 4:919-922.

Colbran JL, Roach PJ, Fiol CJ, Dixon JE, Andrisani OM, Corbin JD (1992) cAMP-dependent protein kinase, but not the cGMP-dependent enzyme, rapidly phosphorylates $\Delta$-CREB, and a synthetic $\Delta$-CREB peptide. Biochem Cell Biol 70:1277-1282.

Davis HP, Squire LR (1984) Protein synthesis and memory: a review. Psychol Bull 96:518-559.

Deisseroth K, Bito H, Tsien RW (1996) Signaling from synapse to nucleus: postsynaptic CREB phosphorylation during multiple forms of hippocampal synaptic plasticity. Neuron 16:89-101.

Deisseroth K, Heist EK, Tsien RW (1998) Translocation of calmodulin to the nucleus supports CREB phosphorylation in hippocampal neurons. Nature 392:198-202.

Ding JM, Faiman LE, Hurst WJ, Kuriashkina LR, Gillette MU (1997) Resetting the biological clock: mediation of nocturnal CREB phosphorylation via light, glutamate, and nitric oxide. J Neurosci 17:667-675.

East SJ, Garthwaite J (1991) NMDA receptor activation in rat hippocampus induces cyclic GMP formation through the L-arginine-nitric oxide pathway. Neurosci Lett 123:17-19.

English JD, Sweatt JD (1997) A requirement for the mitogen-activated protein kinase cascade in hippocampal long-term potentiation. J Biol Chem 272:19103-19106.

Frey U, Morris RG (1997) Synaptic tagging and long-term potentiation. Nature 385:533-536.

Frey U, Krug M, Reymann KG, Matthies H (1988) Anisomycin, an inhibitor of protein synthesis, blocks late phase of LTP phenomena in the hippocampal CA1 region in vitro. Brain Res 452:57-65.

Frey U, Krug M, Brodeman R, Reymann K, Matthies H (1989) Longterm potentiation induced in dendrites separated from rats CA1 pyramidal somata does not establish a late phase. Neurosci Lett 97:135-139.

Frey U, Huang Y-Y, Kandel ER (1993) Effects of cAMP simulate a late stage of LTP in hippocampal CA1 neurons. Science 260:1661-1664.

Galione A, White A, Wilmott N, Turner M, Potter BVL, Watson SP (1993) cGMP mobilizes intracellular $\mathrm{Ca}^{2+}$ in sea urchin eggs by stimulating cyclic ADP-ribose synthesis. Nature 365:456-459.

Garthwaite J, Southam E, Boulton CL, Nielson EB, Schmidt K, Mayer B (1995) Potent and selective inhibition of nitric oxide sensitive guanylyl cyclase by $1 H$-[1,2,4] oxadiazolo[4,3 $\alpha]$ quinoxalin-1-one. Mol Pharmacol 48:184-188.

Gass P, Wolter DP, Balschun D, Rudolph D, Frey U, Lipp H-P, Schutz G (1998) Deficits in memory tasks of mice with CREB mutations depend on gene dosage. Learn Mem 5:274-288.

Geahlen RL, Krebs EG (1980) Regulatory subunit of the type 1 cAMPdependent protein kinase as an inhibitor and substrate of the cGMPdependent protein kinase. J Biol Chem 255:1164-1169.

Geahlen RL, Allen SM, Krebs EG (1981) Effect of phosphorylation on the regulatory subunit of the type $1 \mathrm{cAMP}$-dependent protein kinase. J Biol Chem 256:4536-4540. 
Geiger J, Nolte C, Butt E, Sage SO, Walter U (1992) Role of cGMP and cGMP-dependent protein kinase in nitrovasodilator inhibition of agonist-evoked calcium elevation in human platelets. Proc Natl Acad Sci USA 89:1031-1035.

Ginty DD, Kornhauser JM, Thompson MA, Bading H, Mayo KE, Takahashi JS, Greenberg ME (1993) Regulation of CREB phosphorylation in the suprachiasmatic nucleus by light and a circadian clock. Science 260:238-241.

Gribkoff VK, Lum-Ragan JT (1992) Evidence for nitric oxide synthase inhibitor-sensitive and insensitive hippocampal synaptic potentiation. J Neurophysiol 68:639-642.

Gudi T, Huvar I, Meinecke M, Lohmann SM, Boss GR, Pilz RB (1996) Regulation of gene expression by cGMP-dependent protein kinase. J Biol Chem 271:4597-4600.

Gudi T, Lohmann SM, Pilz RB (1997) Regulation of gene expression by cyclic GMP-dependent protein kinase requires nuclear translocation of the kinase: identification of a nuclear localization signal. Mol Cell Biol 17:5244-5254.

Haby C, Lisovoski F, Aunis D, Zwiller J (1994) Stimulation of the cyclic GMP pathway by NO induces expression of the immediate early genes c-fos and junB in PC12 cells. J Neurochem 62:496-501.

Haley JE, Malen PL, Chapman PF (1993) Nitric oxide synthase inhibitors block long-term potentiation induced by weak but not strong tetanic stimulation at physiological brain temperatures in rat hippocampal slices. Neurosci Lett 160:85-88.

Harvey J, Collingridge GL (1992) Thapsigargin blocks the induction of long-term potentiation in rat hippocampal slices. Neurosci Lett 139:197-200.

Hawkins RD (1996) NO honey, I don't remember. Neuron 16:465-467.

Hawkins RD, Kandel ER, Siegelbaum SA (1993) Learning to modulate transmitter release: themes and variations in synaptic plasticity. Annu Rev Neurosci 16:625-665.

Hawkins RD, Son H, Arancio O (1998) Nitric oxide as a retrograde messenger during long-term potentiation in hippocampus. Prog Brain Res 118:155-172.

Huang Y-Y, Kandel ER (1994) Recruitment of long-lasting and protein kinase A-dependent long-term potentiation in the CA1 region of hippocampus requires repeated tetanization. Learn Mem 1:74-82.

Huang Y-Y, Nguyen PV, Abel T, Kandel ER (1996) Long-lasting forms of synaptic potentiation in the mammalian hippocampus. Learn Mem 3:74-85.

Impey S, Mark M, Villacres EC, Poser S, Chavkin C, Storm DR (1996) Induction of CRE-mediated gene expression by stimuli that generate long-lasting LTP in area CA1 of the hippocampus. Neuron 16:973-982.

Impey S, Obrietan K, Wong ST, Poser S, Shigetoshi Y, Wayman G, Deloulome JC, Chan G, Storm DR (1998) Cross talk between ERK and PKA is required for $\mathrm{Ca}^{2+}$ stimulation of CREB-dependent transcription and ERK nuclear translocation. Neuron 21:869-883.

Kandel ER (1989) Genes, nerve cells, and the remembrance of things past. J Neuropsychiatry Clin Neurosci 1:103-125.

Kang H, Schuman ER (1996) A requirement of local protein synthesis in neurotrophin-induced hippocampal synaptic plasticity. Science 273:1042-1046.

Kantor DB, Lanzrein J, Stary SJ, Sandoval GM, Smith WB, Sullivan BM, Davidson N, Schuman EM (1996) A role for endothelial NO synthase in LTP revealed by adenovirus-mediated inhibition and rescue. Science 274:1744-1748.

Kingston PA, Zufall F, Barnstable CT (1996) Rat hippocampal neurons express genes for both rod retinal and olfactory cyclic nucleotide-gated channels: novel targets for cAMP/cGMP function. Proc Natl Acad Sci USA 93:10440-10445.

Kleppisch T, Pfeifer A, Klatt P, Ruth P, Montkowski A, Fassler R, Hofmann F (1999) Long-term potentiation in the hippocampal CA1 region of mice lacking cGMP-dependent kinases is normal and susceptible to inhibition of nitric oxide synthase. J Neurosci 19:48-55.

Lee HC (1993) Potentiation of calcium- and caffeine-induced calcium release by cyclic ADP-ribose. J Biol Chem 268:293-299.

Malen P, Chapman PF (1997) Nitric oxide facilitates long-term potentiation, but not long-term depression. J Neurosci 17:2645-2651.
Martin KC, Casadio A, Zhu H, E Y, Rose J, Chen M, Bailey CH, Kandel ER (1997a) Synapse-specific, long-term facilitation of Aplysia sensory to motor synapses: a function for local protein synthesis in memory storage. Cell 91:927-938.

Martin KC, Michael D, Rose JC, Barad M, Casadio A, Zhu H, Kandel ER (1997b) MAP kinase translocates into the nucleus of the presynaptic cell and is required for long-term facilitation in Aplysia. Neuron 18:899-912.

Matthies H, Schulz S, Thiemann W, Siemer H, Schmidt H, Krug M, Hölt V (1997) Design of a multiple slice interface chamber and application for resolving the temporal pattern of CREB phosphorylation in hippocampal long-term potentiation. J Neurosci Methods 78:173-179.

Michael D, Martin KC, Seger R, Ning MM, Baston R, Kandel ER (1998) Repeated pulses of serotonin required for long-term facilitation activate mitogen-activated protein kinase in sensory neurons of Aplysia. Proc Natl Acad Sci USA 95:1864-1869.

Nguyen PV, Kandel ER (1997) Brief theta-burst stimulation induces a transcription-dependent late phase of LTP requiring cAMP in area CA1 of the mouse hippocampus. Learn Mem 4:230-243.

Nguyen PV, Abel T, Kandel ER (1994) Requirement of a critical period of transcription for induction of a late phase of LTP. Science 265:1104-1107.

O'Dell TJ, Huang PL, Dawson TM, Dinerman JL, Snyder SH, Kandel ER, Fishman MC (1994) Endothelial NOS and the blockade of LTP by NOS inhibitors in mice lacking neuronal NOS. Science 265:542-546.

Ohki K, Yoshida K, Hagiwara M, Harada T, Takamura M, Ohashi T, Matsuda H, Imaki J (1995) Nitric oxide induces $c$-fos gene expression via cyclic AMP response element binding protein (CREB) phosphorylation in rat retinal pigment epithelium. Brain Res 696:140-144.

Peunova N, Enlkolopov G (1993) Amplification of calcium-induced gene transcription by nitric oxide in neuronal cells. Nature 364:450-453.

Repaske DR, Corbin JG, Conti M, Goy MF (1993) A cyclic GMPstimulated cyclic nucleotide phosphodiesterase gene is highly expressed in the limbic system of the rat brain. Neuroscience 56:673-686.

Schuman EM, Madison DV (1994) Locally distributed synaptic potentiation in the hippocampus. Science 263:532-536.

Sekhar KR, Hatchett RJ, Shabb JB, Wolfe L, Francis SH, Wells JN, Jastorff B, Butt E, Chakinala MM, Corbin JD (1992) Relaxation of pig coronary arteries by new and potent cGMP analogs that selectively activate type I alpha, compared with type I beta, cGMP-dependent protein kinase. Mol Pharmacol 42:103-108.

Son H, Hawkins RD, Martin K, Kiebler M, Huang PL, Fishman MC, Kandel ER (1996) Long-term potentiation is reduced in mice that are doubly mutant in endothelial and neuronal nitric oxide synthase. Cell 87:1015-1023.

Son H, Lu Y-F, Zhuo M, Arancio O, Kandel ER, Hawkins RD (1998) The specific role of cGMP in hippocampal LTP. Learn Mem 5:231-245.

Wang Y, Wu J, Rowan MJ, Anwyl R (1996) Ryanodine produces a low frequency stimulation-induced NMDA receptor-independent longterm potentiation in the rat dentate gyrus in vitro. J Physiol (Lond) 495:755-767.

Wexler EM, Stanton PK, Nawy S (1998) Nitric oxide depresses GABA receptor function via coactivation of cGMP-dependent kinase and phosphodiesterase. J Neurosci 18:2342-2349.

Winder DG, Mansuy IM, Osman M, Moallem TM, Kandel ER (1998) Genetic and pharmacological evidence of a novel, intermediate phase of long-term potentiation suppressed by calcineurin. Cell 92:25-37.

Zhuo M, Small SA, Kandel ER, Hawkins RD (1993) Nitric oxide and carbon monoxide produce activity-dependent long-term synaptic enhancement in hippocampus. Science 260:1946-1950.

Zhuo M, Hu Y, Schultz C, Kandel ER, Hawkins RD (1994) Role of guanylyl cyclase and cGMP-dependent protein kinase in long-term potentiation. Nature 368:635-639.

Zhuo M, Laitinen JT, Li X-C, Hawkins RD (1998) On the respective roles of nitric oxide and carbon monoxide in long-term potentiation in the hippocampus. Learn Mem 5:467-480. 